\title{
Laicismo y educación pública en el discurso liberal ecuatoriano (1897-1920): una reinterpretación*
}

\author{
Rosemarie Terán Najas
}

Profesora de la Universidad Andina Simón Bolívar(Ecuador). Correo electrónico: rteran_najas@yahoo.es. La autora es magíster en Historia Andina de la Facultad Latinoamericana de Ciencias Sociales-FLACSO (Ecuador) y doctora en Formación Histórica y Comparada en Educación de la Universidad Nacional de Educación a Distancia-UNED (España). Entre sus publicaciones recientes tenemos: "Representaciones visuales de una utopía misionera: los salesianos en la amazonía (1890-1930)". En la mirada del otro, Acervo documental del vicariato apostólico salesiano en la amazonía ecuatoriana, 1890-1930, en La mirada del Otro, Memoria del Mundo. Ecuador: UNESCO-Instituto Nacional de Patrimonio Cultural del Ecuador (2015) y "Educación, cambio institucional y equidad". En Ecuador: desafíos para el presente y el futuro, F. Balseca y C. Montúfar (edits). Ecuador: Universidad Andina Simón Bolívar (2015). Entre sus temas de interés están historia social y cultural, historia de la educación.

Recibido: 19 de noviembre de 2015

Aprobado: 21 de abril de 2016

Modificado: 30 de abril de 2016

Artículo de investigación científica

DOI: http://dx.doi.org/10.15648/hc.30.2016.4

* $\quad$ Este artículo forma parte del proyecto: "Historia de la educación laica y los procesos de secularización en América Latina y el Caribe” financiación propia.

Esta publicación está bajo una licencia Creative Commons Reconocimiento-NoComercial 4.0 


\title{
Laicismo y educación pública en el discurso liberal ecuatoriano (1897-1920): una reinterpretación
}

\section{Resumen}

El trabajo explora el carácter peculiar que adquiere el laicismo en el Ecuador como concepto central de la reforma educativa que surge de la revolución liberal de 1895 y se despliega en las dos primeras décadas del siglo XX. En tal contexto, se analizan las imbricaciones entre las concepciones de "educación laica” y "educación pública", presentes en los marcos legales y el nuevo aparato educativo, así como las polémicas acerca de los niveles de secularización del nuevo sistema escolar y la perpetuación de formas sacralizadas de representación. Se identifica la apropiación del laicismo en el discurso pedagógico del maestro normalista y en la consolidación de su identidad social y profesional.

Palabras clave: laicismo, revolución liberal, educación laica, normalismo, positivismo, historia ecuatoriana.

\section{Secularism and Public Education in the ecuadorian liberal discourse (1897- 1920): a reinterpretation}

\begin{abstract}
This paper explores the distinguishing character acquired by secularism in Ecuador as a central concept of educational reform that arises from the liberal revolution of 1895 and takes place in the first two decades of the twentieth century. In such a context, it is analyzed the overlaps between the conceptions of "secular education" and "public education" presented in the legal frameworks and the new educational system, and the controversies about the levels of secularization of the new school system and the perpetuation of hallowed forms from representation. The appropriation of secularism is identified in the normal school teachers pedagogical discourse and, in the consolidation of their social and professional identity.
\end{abstract}

Keywords: secularism, liberal revolution, secular education, teacher-training, positivism, history of Ecuador. 


\section{Laicismo e educação pública no discurso liberal equatoriano (1897-1920): uma representação}

\section{Resumo}

O trabalho explora o carácter peculiar que adquire o laicismo no Equador como conceito central da reforma educativa que surge da revolução liberal de 1895 e se despliega nas duas primeiras décadas do século XX. Em tal contexto, analisam-se entrelaçamento entre as concepções da "educação laica" e "educação pública", presentes nos marcos legais e o novo aparelho educativo, bem como as polémicas a respeito dos níveis de secularização do novo sistema escolar e a perpetuação de formas sacralizadas de representação. Identifica-se a apropriação do laicismo no discurso pedagógico do mestre normalista e na consolidação de sua identidade social e profissional.

Palavras-chave: laicismo, revolução liberal, educação laica, normalismo, positivismo, história equatoriana.

\section{Laïcisme et Éducation Publique dans le discours libéral équatorien (1897-1920): une réinterprétation}

\section{Résumé}

Le travail explore le caractère particulier acquis par le laïcisme en Équateur en tant que concept central de la réforme éducative qui surgit de la révolution libérale de 1895 et qui se déploie dans les deux premières décennies du XXe siècle. Dans ce contexte, on analyse les imbrications entre les conceptions d' «éducation laïque» et «éducation publique», présentes dans les cadres légaux et dans la nouvelle structure éducative, ainsi que les débats sur les niveaux de sécularisation du nouveau système scolaire et la perpétuation de formes sacralisées de représentation. On identifie l'appropriation du laïcisme dans le discours pédagogique du maître normalien et dans la consolidation de son identité sociale et professionnelle.

Mots clés: laïcisme, révolution libérale, éducation laïque, normalien, positivisme, histoire équatorienne.

Este artículo examina la construcción del discurso laicista durante las décadas que rodearon las medidas de secularización de la enseñanza (1906), 
con el fin de identificar sus significados cambiantes en correspondencia con las políticas relativas a la instrucción pública. En el abordaje de este tema por parte de los estudios históricos en el Ecuador ha predominado una perspectiva reivindicativa del laicismo, que fue fraguada, en realidad, en el contexto de la década de 1940, ante la decisión de la Asamblea Constituyente de 1947 de restaurar el subsidio oficial a la enseñanza religiosa que había sido suspendido en 1906 por el Estado liberal. En ese marco, los sectores que abrazaron el laicismo hicieron importantes declaraciones y publicaron numerosas obras académicas dirigidas a defender la educación laica, resaltar su rol en el fortalecimiento de la identidad y la soberanía nacionales; así como también su papel modernizador del Estado y la sociedad. De otro lado, a esas alturas el laicismo ya era el sello de identidad de incontables personajes de la intelectualidad y la política, orgullosos de pertenecer a verdaderos linajes familiares de maestros y maestras laicas, herederos de las clases medias emergentes tributarias de la revolución liberal. Hasta 1951, fecha de celebración de los 50 años de creación de las primeras normales laicas, que también dio lugar a un importante relato conmemorativo $^{1}$, se creó el escenario para la construcción de una mitología y una genealogía del laicismo que, salvo contadas excepciones, ha articulado hasta el presente la comprensión e interpretación de la historia de la educación ecuatoriana de la primera mitad del siglo $\mathrm{XX}^{2}$.

1 Libro Del cincuentenario de la fundación de los colegios normales Manuela Cañizares y Juan Montalvo, 1901-1951 (Quito: Imprenta Nacional, 1907). Se trata de una obra que incluye numerosos ensayos de los normalistas formados por las misiones alemanas. Gracias a la exploración de los archivos de las normales efectuada expresamente para la conmemoración se pudo incluir en la obra algunos de los pocos documentales fundacionales que se habían conservado.

2 Las obras de Enrique Ayala Mora y Gabriela Ossenbach salen de esta tendencia e informan sobre el proceso desde una perspectiva crítica y basada en abundante trabajo de archivos. Ver del primero Historia de la revolución liberal (Quito: Corporación Editora Nacional-Taller de Estudios Históricos, 1994). Gabriela Ossenbach, especialmente, contribuye a la desmitificación del tema en varias de sus obras, particularmente en Formación de los sistemas educativos nacionales en Hispanoamérica, La política educativa como factor de consolidación del Estado Nacional (1870-1900). El caso del Ecuador (Tesis Doctoral en Historia de la Educación, Universidad de Oviedo, UNED, 1988); y "La educación laica en las reformas liberales del Ecuador entre 1827 y 1912", en École et église en Espagne et en Amérique Latine. Aspects idéologiques et institutionnels, Actes du Colloque de Tours, 4-6 décembre 1987 (Publications de l'Université de Tours, 1988), 405-434. En la línea de consagrar a la misión alemana como un hito en la consolidación del lacisimo ver Emmanuelle Sinardet, "La pedagogía al servicio de un proyecto político: el herbartismo y el liberalismo en el Ecuador (1895-1925)", Procesos, Revista Ecuatoriana de Historia, 13 (II semestre/1998-I semestre 1999): 25-41; y Jorge Gómez, Las misiones pedagógicas alemanas y la educación en el Ecuador (Quito: Ediciones Abya Yala, 1993). 
El arco temporal considerado es el intervalo 1897-19203 que constituye el escenario de la reforma educativa liberal propiamente dicha. Las acciones iniciales de mayor contenido simbólico fueron la creación en 1897 del Colegio Mejía ${ }^{4}$, que será uno de los pocos baluartes de la enseñanza secundaria laica en todo el periodo, y el establecimiento de las primeras normales laicas en 1901, varias de las cuales fueron suspendidas en años posteriores por falta de recursos y maestros. Hasta la oficialización de la enseñanza laica en 1906, no existían más de 30 normalistas egresados. Los informes de los ministros del ramo deploraban el bajo presupuesto y la improvisación observada en el conjunto de la reforma; además de la desarticulación estructural del sistema educativo que impedía unificar cualquier política ${ }^{5}$. Esta primera etapa se cierra con el asesinato del líder legendario de la revolución liberal, Eloy Alfaro, aquejado para entonces por su impopularidad y las inevitables tensiones sociales que provocó su revolución al movilizar las bases populares contra los grupos oligárquicos, y al mismo tiempo, crear contradictorias e insostenibles alianzas tanto con las minorías de terratenientes como con sectores de la burguesía, el ejército y tendencias opuestas dentro del propio liberalismo ${ }^{6}$.

Luego de la muerte del caudillo, la reforma pierde su impulso revolucionario pero entra en una etapa de relativa institucionalización con la contratación en 1913 de la primera misión alemana, portadora del método herbartiano, a la que se le encarga la dirección de la formación docente a

3 La jefatura suprema de Eloy Alfaro se proclama el 5 de junio de 1895 en el marco de un golpe de Estado. Se atribuye a este gobernante reformas sociales que contribuyen a la inserción de la mujer en la educación, la organización de la clase obrera y la protección a la población indígena, además de la obra del ferrocarril nacional. Con el ascenso al poder de su sucesor Leonidas Plaza (19011905/1912-1916) se instala un liberalismo moderado que, sin embargo, concreta la separación Estado-Iglesia, la Ley del Matrimonio Civil y del Divorcio, y la secularización de la enseñanza legislada por la convención de 1906. Con el asesinato de Alfaro en 1911 arranca el liberalismo "plutocrático", aliado del poder económico, al que corresponden la segunda presidencia de Plaza y el gobierno de Alfredo Baquerizo Moreno (1916-1920), con el cual se cierra el marco temporal del presente texto. Parte de la reflexión incluida en este artículo proviene de la tesis de Rosemarie Terán Najas, "La escolarización de la vida. El esfuerzo de construcción de la modernidad educativa en el Ecuador (1821-1921)" (Tesis Doctoral en Historia de la Educación, UNED, 2014).

4 José Mejía Lequerica (1775-1813) fue diputado en las cortes de Cádiz durante la etapa independentista, y el liberalismo reivindicó su figura al convertirlo en patrono del primer colegio laico.

5 Informe del Ministro de Instrucción Pública a la Nación (Quito: Imprenta Nacional, 1907), 168-170.

6 Enrique Ayala Mora, Historia de la revolución liberal..., 197. 
nivel nacional hasta el arribo de una siguiente misión en 1921. La llegada de esta última misión, particularmente, ha sido consagrada por la mitología laica como el hito principal de la reforma educativa y el más representativo para el laicismo, en tanto se considera que los principios herbartianos guardaban total consonancia con el ideario laico de la modernización y el progreso $^{7}$. De hecho, detrás de este discurso, lo que estaba en juego era la identidad de los docentes formados con la segunda misión alemana, que crearon el relato celebratorio de la trayectoria normalista ecuatoriana en el cincuentenario de fundación al que nos hemos referido al principio.

Con el fin de interrogar la narrativa mitológica predominante hasta el momento, esta ponencia se propone analizar los contextos de enunciación de algunos discursos relevantes en torno al laicismo en la época señalada. En la primera parte, se explora la dimensión política de la problemática a partir del debate librado en la Constitución de 1906 sobre la secularización de la enseñanza, y de la polémica relativa a la separación Estado-Iglesia en la perspectiva de José Peralta, uno de los políticos cercanos a Alfaro de mayor influencia en la etapa revolucionaria ${ }^{8}$. En una segunda parte, destinada al discurso pedagógico, se aborda tanto la visión de la educación laica en la obra del pedagogo Fernando Pons ${ }^{9}$, activo defensor de la misma en el marco de la polémica desatada en 1906, como los sentidos de lo sagrado en dos textos escolares de gran arraigo en el medio escolar de la etapa posalfarista.

$7 \quad$ Ver Jorge Gómez, Las misiones pedagógicas alemanas y la educación en el Ecuador (Quito: Ediciones Abya Yala, 1993); Emannuelle Sinardet, "La pedagogía al servicio de un proyecto político: el herbartismo y el liberalismo en el Ecuador 1895-1925”, Procesos: Revista Ecuatoriana de Historia, 13 (1998-1999).

8 José Peralta (1859-1937) fue un destacado político liberal de gran influencia en la vida pública del Ecuador a partir del triunfo de la revolución de 1895. Sus reflexiones políticas se concretaron en ensayos, artículos y libros que modelaron la intensa polémica desatada en la época sobre los marcos doctrinarios del liberalismo. Dirigió algunos ministerios, fue catedrático universitario y diputado de la convención de 1906.

9 El pedagogo español Fernando Pons, nacionalizado en Ecuador, fue contactado por el gobierno alfarista para desempeñar el cargo de rector de la Normal de Varones entre 1906-1908. Lideró el primer movimiento pedagógico de la etapa liberal, formado en torno a la enseñanza intuitiva, y promovió las primeras organizaciones docentes entre los jóvenes maestros laicos. Su obra Metodología General (1913) constituye el más actualizado, exhaustivo y riguroso tratado pedagógico que se haya registrado en el medio educativo de la época. 
Partimos de la consideración de que en sus inicios el laicismo ecuatoriano se nutrió básicamente de una matriz anticlerical que, aunque favoreció los procesos de secularización institucional, limitó al mismo tiempo las posibilidades de transitar hacia un proyecto político más amplio orientado a la consecución de un verdadero modelo de soberanía popular.

En esta perspectiva, el rasgo anticlerical del laicismo ecuatoriano tampoco significó un cuestionamiento real al carácter sacralizado del poder. El Ecuador venía de una experiencia de larga duración de convivencia con el catolicismo, una ideología que había moldeado por más de 40 años tanto la estructura del poder como los distintos órdenes de la vida social, y cuya hegemonía había sido cuidadosamente resguardada por los sectores conservadores oligárquicos que cooptaron el Estado entre 1869 y $1894^{10}$. Esta pesada herencia pudo ser superada en el plano de la diferenciación entre religiosidad y confesionalidad, una cuestión clave puesta a discusión por el historiador Roberto Blancarte que permite interrogar las fronteras entre lo religioso y lo laico ${ }^{11}$. El catolicismo aparece entonces como un fenómeno cultural no necesariamente dependiente del Estado. Una vez secularizado, el Estado se habría visto obligado a encontrar nuevas fuentes de sacralización del poder para fundamentar el orden del Estado laico. Tal fenómeno en el caso ecuatoriano restringirá la trascendencia de los procesos de secularización de la enseñanza, obligando a negociar con la herencia católica los términos del nuevo sistema educativo. A diferencia del laicismo militante de la etapa alfarista, luego del asesinato de Alfaro se irá debilitando la línea anticlerical. Un laicismo distinto resurgirá aso-

10 El presidente conservador Gabriel García Moreno (1869-1875) encontró en el catolicismo el elemento unificador que permitió configurar la primera versión propiamente dicha de Estado-nación. Los continuadores de su proyecto, integrantes del llamado "progresismo"(1883-1895), perpetuaron su obra en clave menos autoritaria. Ver Enrique Ayala Lucha política y origen de los partidos en Ecuador (Quito: Corporación Editora Nacional-Taller de Estudios Históricos, 1988).

11 Adscribimos a las tesis de Blancarte para señalar que el Ecuador habría participado de la tendencia presente -en mayor o menor grado- en América Latina de asimilar la laicidad a la cuestión de la separación Iglesia-Estado, más que a una nueva institucionalidad política. Las oligarquías liberales de América Latina, tal como señala dicho autor, se habrían dedicado a reducir la riqueza material de la iglesia, sin cuestionar las fuentes del poder religioso como tal, lo cual obstaculizó el camino a la consecución de una verdadera soberanía popular en los nuevos regímenes liberales. Ver del autor, "Laicidad y laicismo en América Latina", Estudios Sociológicos, Vol. 26, No. 76 (Enero-Abril, 2008): 157. 
ciado al saber pedagógico positivista emergente y al ideal regenerador de la escuela, ambos aspectos decisivos en la construcción identitaria de los docentes laicos.

\section{LA ASIMILACIÓN DE LO PÚBLICO A LO LAICO}

La Constitución de 1897 que siguió al golpe de estado liberal de 1895, no solo que no incorporó artículos referidos a la secularización sino que, bajo la influencia de una mayoría liberal moderada, mantuvo al catolicismo como religión oficial con exclusión de otros cultos ${ }^{12}$. En el acápite de "garantías", no obstante, se logró incluir un reconocimiento a las creencias religiosas y la obligación del Estado de respetar sus expresiones, medida que fue duramente rechazada por la jerarquía eclesiástica con el pretexto de que constituía una amenaza para la unidad nacional. Una reforma trascendental adoptada también en 1897 fue la descentralización del aparato escolar que privó de varias atribuciones al Ministerio de Instrucción ${ }^{13}$. Sus impulsadores no se imaginaron, en ese entonces, que esta medida crearía en lo posterior las condiciones para la continuidad del modelo corporativo de la educación católica dentro del marco liberal ${ }^{14}$.

Entre las primeras medidas abiertamente secularizadoras de la Constitución de 1897 se incluyeron el impedimento para que los religiosos desempeñaran cargos públicos y la prohibición de la inmigración de comunidades religiosas, tema derivado del sentido nacionalista que esgrimió el laicismo frente a la educación confesional, a la que se calificaba de "extranjerizante"15. En 1899 se creó la Ley del Patronato, que ponía en manos del

12 Enrique Ayala, Historia de la revolución liberal ecuatoriana..., 113.

13 Julio Tobar Donoso, "La Instrucción Pública de 1830 a 1930. Apuntes para su historia"., en J. Gonzalo Orellana (editor) El Ecuador en cien años de Independencia (Quito, Escuela Tipográfica Salesiana,1930) 307. Gabriela Ossenbach en Formación de los sistemas educativos nacionales en Hispanoamérica..., dedica una buena parte de su reflexión a demostrar que el estado liberal ecuatoriano experimentó una tensión entre la necesidad de centralizar o unificar políticas educativas y las dinámicas de descentralización que caracterizaron a la administración pública.

14 Los gobiernos progresistas católicos, continuadores de la obra educativa de García Moreno, moderaron el centralismo del aparato educativo garciano, al restaurar la relación entre las municipalidades y la educación, ver Rosemarie Terán Najas, "La escolarización de la vida...., 112.

15 La acusación de extranjerizante que recayó sobre la educación confesional heredada de los gobiernos conservadores fue la base para argumentar un sentido de soberanía. En los años 40, en la coyuntura de resurgimiento de un laicismo militante, se sostenía que el Estado laico y la educación laica garantizaban la soberanía nacional. 
Ejecutivo el nombramiento de nuncios y la autorización para el establecimiento de órdenes religiosas; además de suprimir las rentas eclesiásticas, instituyendo a cambio el subsidio del Estado hacia la Iglesia. Gracias al espíritu de negociación con los sectores conservadores que imperó durante el gobierno de Leonidas Plaza, sucesor de Alfaro, se pudo profundizar la secularización institucional al decretarse en 1902 las leyes de Registro, Matrimonio Civil y Divorcio; en 1904 la Ley de Cultos, y en 1908 la Ley de Beneficencia, que transfirió al Estado los bienes de las comunidades religiosas. El combate en contra de la Iglesia se impregnó de un sentido patriótico, como respuesta a la existencia de órdenes religiosas extranjeras que por décadas tuvieron a su cargo la educación pública ${ }^{16}$.

La declaración del carácter laico de la instrucción pública llegó de la mano de la oficialización de la separación Iglesia-Estado proclamada por las Constituciones de 1905 y 1906, esta última durante el segundo mandato de Alfaro. Su imposición activó las mayores tensiones sociales registradas en el largo camino de la secularización desde 1895. Con esta separación, por primera vez la Iglesia se vio despojada de su carácter de persona jurídica de derecho público.

Para los liberales anticlericales que impulsaron la secularización definitiva de la enseñanza en 1906, la equivalencia entre educación pública y laica se convirtió en una característica de su retórica política ${ }^{17}$. A tal punto quiso imponer el anticlericalismo su sesgo al aparato de instrucción que en el cuerpo legal lo público aparecía como un elemento subordinado a lo laico. En ese contexto, el significado del laicismo se asimiló a estatismo, que fue la tendencia visible defendida por el liberalismo "radical", interesado por consolidar la separación Iglesia-Estado. La preeminencia de lo laico en el espíritu de la ley llevó a decir a Nicolás Vega, Director de Estudios de Pichincha, en 1907, que la frontera difusa existente entre los significados de "pública" y "laica" daba lugar a dos ideas de instrucción, una pública

16 Gabriela Ossenbach, "La secularización del sistema educativo y de la práctica pedagógica: laicismo y nacionalismo”, Procesos, Revista Ecuatoriana de Historia, 8 (I sem/1995-II sem/1996): 35-36.

17 La ley de separación Iglesia-Estado francesa de 1905 fue el factor que precipitó la secularización en el Ecuador, medida que no obstante haber sido adoptada en ese mismo año, solo se pudo formalizar en 1906. 
oficial y una pública no oficial, cuestión que impedía saber en cuál tipo de establecimientos se podía exigir la enseñanza laica" ${ }^{18}$, lo que en opinión del liberal Alfredo Espinoza Tamayo, dejaba en libertad a las escuelas municipales y particulares ${ }^{19}$. De allí derivaron buena parte de los tropiezos que enfrentaron los gobiernos liberales para configurar un verdadero sistema de instrucción pública.

La incapacidad de transitar desde un sistema de poder fundado en lo sagrado a otro basado en la soberanía del pueblo, como corresponde al paradigma laico ${ }^{20}$, tuvo también relación, en el caso del liberalismo estatista anticlerical ecuatoriano, con el temor a que la acción popular desbordara los cauces establecidos. Las Constituciones liberales de 1897 y 1906 hicieron descansar la soberanía en una concepción de nación a la que se concebía como una esfera reservada para ciertos sujetos políticos que podían exhibir la condición de "ciudadanos", en contraposición con la mayoría representada por los "pueblos", carentes desde esa óptica de autodeterminación política. De forma consecuente con estas premisas, y poniendo en tela de juicio su radicalidad, la mayoría liberal de la Asamblea de 1906 renunció expresamente a reconocer alguna filiación política con la revolución francesa -que sí fue reclamada por los pocos militantes del liberalismo popular- para, a cambio, abrazar explícitamente el legado hispanista de Cádiz, que consagró a la nación como depositaria de la soberanía.

¿Cómo se podía gobernar con legitimidad a partir de este concepto restringido de ciudadanía? Si bien los liberales no apelaron expresamente a un mecanismo religioso, sí lo hicieron a una concepción metahistórica de nación forjada sobre la base de configurar una genealogía constitucional anclada en la cultura política hispana. De esa manera, encadenándolo a la tradición, se deslegitimó la posibilidad de que el "pueblo" ecuatoriano pudiera forjar su propio destino en el marco de una revolución que a esas alturas prefería el "orden" a la "libertad". Fue por estas razones que el ar-

18 Nicolás Vega, "Breves observaciones a la Ley Orgánica de Instrucción Pública" (Quito, Imprenta Nacional, 1906).

19 Informe del Ministro de Instrucción Pública...1907, 46.

20 Roberto Blancarte, "Laicité au Mexique et en Amerique Latine. Comparaisons", Archives des Sciencies Sociales des religions, 146 (avril-juin 2009): 18. 
tículo tercero de la Constitución de 1906, declaró efectivamente que la soberanía descansaba en la Nación. Se puede concluir entonces, retomando la perspectiva de Blancarte, que la lucha política concentrada en el Ecuador en torno a la separación Iglesia-Estado fue más bien una expresión de la lógica militante y combativa del "laicismo", antes que una "laicidad" sustentada en procesos de institucionalización y democratización ${ }^{21}$.

\section{UN LIBERALISMO NO LAICISTA}

A la línea liberal estatista se opuso en la Asamblea de 1906 un liberalismo concentrado en la defensa de la tolerancia y la libertad de conciencia, principios a los cuales, contrariamente a lo sucedido con la tendencia opuesta, debió subordinarse el laicismo. Esta posición representada por José Peralta, ministro y hombre de confianza de Eloy Alfaro, fue determinante en la discusión acerca del carácter del sistema educativo laico. En el pensamiento tolerante de Peralta, el laicismo militante no ocupó un lugar central ni decisivo, pese a que él se había declarado crítico del papel del clero, al que insistentemente calificaba de "nefasto". En un opúsculo titulado La cuestión religiosa y el poder público en el Ecuador ${ }^{22}$, escrito en respuesta al rechazo de que fue objeto por su apoyo al establecimiento del Patronato, Peralta sostenía:

"Ayer combatí sin tregua los abusos de la clerecía y las aberraciones del ultramontanismo; y hoy con igual tesón defiendo la libertad de conciencia para los ecuatorianos católicos. Si no lo hiciera así, no fuera liberal, no sostendría mi bandera, no cumpliría mi deber" 23 .

A Peralta le interesaba destacar la fuerza que poseía la tradición católica en el país para argumentar que la religión era la mejor garantía de unidad y

21 Roberto Blancarte, "Laicité..., 22.

22 José Peralta, La cuestión religiosa y el poder público en el Ecuador, Quito: Tipografía de la Escuela de Artes y Oficios, 1901.

23 José Peralta, La cuestión religiosa, 21. 
que el Estado-Nación no podía prescindir de ella para gobernar, en tanto constituía la "única fuente de autoridad y de la ley"24.

La singularidad del liberalismo practicado por Peralta radicó en una contradictoria combinación entre anticlericalismo y defensa de la relación Iglesia-Estado. En realidad, refiriéndose al papel de la religión, sostuvo que la administración pública estaba obligada a expresar "el espíritu general" de un pueblo, entendiendo este concepto como el "conjunto de las ideas y máximas aceptadas por él (pueblo)”. No obstante, esta tarea moral atribuida al aparato público no significaba al mismo tiempo que Peralta tuviera una posición favorable a la estatización, entre otras razones porque su noción de Estado se inspiraba en el ideario republicano corporativista heredado del sistema de educación católica previo a la revolución liberal. En ese sistema, que se deslindó del modelo centralista garciano, la educación adquirió un carácter descentralizado, fortalecido por relaciones de apoyo que organizaciones de laicos y municipalidades prestaban a la educación católica, todo ello bajo la inspiración del "catolicismo social" El Estado liberal no logró, finalmente, unificar esta estructura, como hubieran querido los liberales radicales.

Pese a la voluntad de consolidar la instrucción pública en clave laica, los resultados finales se decantaron sorpresivamente en la línea trazada por Peralta, puesto que la Ley de Educación de 1907, sucedánea de la Constitución de 1906, no incorporó el artículo constitucional relativo a la prohibición del Estado de financiar otro tipo de enseñanza que no fuera la seglar y municipal. La Ley de Educación se limitó a señalar que "la Instrucción pública oficial será laica, y además gratuita y obligatoria la que se refiere a la enseñanza primaria" ${ }^{26}$. Se postergaron por un año las medidas orientadas a prohibir que las municipalidades siguieran auspiciando la educación católica, y se mantuvo el esquema descentralizado de organización escolar, que otorgaba poco margen de gestión al Ministerio de Instrucción

26 Ley Orgánica de Instrucción Pública (Quito, Imprenta Nacional, 1907). 
sobre la enseñanza primaria fiscal, poniendo en vilo el proyecto de educación popular. Con ello el sistema escolar no pudo encuadrarse del todo en el modelo estatista por el que votó la Convención. Los desacuerdos entre liberales y la encarnizada presión social liderada por la Iglesia fueron probablemente los factores en juego.

En el nuevo contexto de la secularización de la enseñanza la educación católica tuvo que reorientar sus reivindicaciones a la defensa de la educación particular, lo que le permitirá acceder a la contribución económica solidaria de las élites conservadoras. Todo ello significó que la "enseñanza libre" no quedara restringida como aspiraba el artículo 19 de la Constitución ${ }^{27}$. A la larga cobró estatus y posibilidades de desarrollo, frente a los problemas de indefinición institucional que afectaban la oferta educativa fiscal.

Peralta, al igual que el arzobispo González Suárez -el exponente intelectual de mayor prestigio del sector conservador católico- sabía que la polarización política suscitada por la cuestión de la secularización del Estado solo podía ser resuelta por la vía de la negociación. Peralta planteó un liberalismo no laicista, y el arzobispo un reconocimiento a la existencia del liberalismo, que sin embargo no lo llevó a renunciar del todo a la dura crítica esgrimida en su opúsculos contra la educación laica ${ }^{28}$. Ambos se convirtieron en mediadores del largo y accidentado proceso de secularización que vivió el Ecuador en el marco de las transformaciones operadas por la revolución liberal de 1895.

27 Rezaba el famoso artículo 19 de la Constitución de 1906: "La enseñanza es libre con sujeción a las leyes respectivas; pero la enseñanza oficial y la costeada por las municipalidades son esencialmente seglares y laicas. La enseñanza primaria y la de Artes y Oficios son gratuitas, y la primera además obligatoria; sin prejuicio del derecho de los padres para dar a sus hijos lo que hubieren a bien. Ni el Estado ni las municipalidades subvencionarán ni auxiliarán en forma alguna a otras enseñanzas que no fueran la oficial y municipal”, Actas de la Asamblea Nacional de 1906, Fondo Constituciones, Archivo del Palacio Legislativo, Ecuador.

28 Afirmaba el obispo que "la educación cristiana transforma moralmente al niño, lo ilustra y lo fortalece, y en la hora del combate entre el vicio y la virtud lo sostiene (...); la educación laica debilita la voluntad para el bien, enardece las pasiones e irrita los apetitos; el niño se alimenta con el deleite, que lo enerva y enflaquece; repugna el trabajo, huye de todo lo que le exige sacrificios (...). La educación laica es eficacísima para fomentar las pasiones malévolas y atizar las inclinaciones ruines del ser humano”: González Suárez, Boletín Eclesiástico, 16 (Quito, septiembre 1 de 1906), 693. 


\section{LOS SIGNIFICADOS DEL LAICISMO ENTRE LOS MAESTROS LAICOS}

En la etapa que se abre luego del asesinato de Eloy Alfaro (1912), el entusiasmo revolucionario se debilita y con él pierde impulso el apoyo oficial a la reforma educativa laica, golpeada además por el contexto de crisis económica que preanuncia el ocaso del liberalismo de fines de los años 20. Sin embargo, es en ese mismo escenario donde emerge el actor social que va a impulsar el proyecto educativo laicista desde un sentido de apropiación distinto al imperante en el discurso político. Se trata de las primeras promociones de normalistas que empiezan a figurar en el escenario público como agentes activos de la reforma educativa laica.

En ese medio docente no solo se difundió un "nuevo fermento laico de nacionalidad" en reemplazo de la identidad nacional católica, como lo señala Gabriela Ossenbach, sino que se gestó un tipo de discurso laicista estructurado por el paradigma positivista, convertido para entonces en uno de los principales ejes articuladores del saber pedagógico gestado por el normalismo. El exponente más ilustrado en este campo fue el pedagogo catalán Fernando Pons, contactado por el mismo Alfaro durante su exilio en Costa Rica, cuando aquel fungía de catedrático de la Escuela Normal. En el Ecuador, Pons dirigió la Normal de Varones entre 1906-1908, justo en medio del clima de tensiones desatado por la secularización de la enseñanza. Su defensa de la educación laica constituye la expresión más importante del laicismo militante de la etapa alfarista.

La matriz positivista del discurso de Pons se devela en su explicación evolucionista del papel histórico del laicismo. Pons interrelaciona el momento que vivía el desarrollo de la pedagogía como ciencia con el momento que experimentaba la humanidad bajo el influjo de la racionalidad positivista, a la que concebía como una conquista de la civilización. Consideraba que en ambos aspectos se había alcanzado la cumbre del desarrollo occidental y que "la escuela laica" era "la escuela del porvenir: consecuencia natural de la evolución de los pueblos" 29 . A partir de esta premisa encuentra en

29 Fernando Pons, Metodología General, en Pensamiento Pedagógico Ecuatoriano, Segunda Parte (Quito, Ministerio de Cultura / Corporación Editora Nacional, 2011), 165-166. 
las leyes de la evolución natural un fundamento "científico" tanto para explicar el surgimiento de la escuela laica como para definir el método pedagógico más adecuado. La enseñanza -decía parafraseando a Spencer y Comte- debía ser en pequeño la repetición de la historia de la civilización". Pons explica estas ideas en detalle en los siguientes párrafos de su Metodología General:

"...muchos pedagogos afirman, sin reserva alguna, que hoy se debe enseñar de la misma manera como se aprendiera antes (...) Aquellos hombres para realizar el progreso que alcanzaron, no pudieron disponer de otras luces ni de otros auxilios que las inspiraciones de su propio ingenio. Por otra parte, el camino que debieron seguir no estaba trazado; ellos tuvieron que construirlo, y en esto hubo $(. .$.$) muchos tropiezos y hasta retrocesos (. .$.$) . No$ ocurre lo mismo cuando se trata de enseñar la verdad, cuando se trata de instruir a los demás. En este (nuestro) caso, la verdad está ya hallada, y el camino que hay que seguir es conocido y está ya trazado. De suerte que la labor del maestro y del discípulo son mucho más fáciles y cómodas: la del maestro porque ya lo tiene todo previsto y arreglado; y la del discípulo porque cuenta siempre con la guía y dirección del maestro" 30 .

En el marco de la reflexión de Pons, de forma "natural" el maestro laico se situaba a la cabeza del proceso modernizador, porque estaba destinado a conducir al niño en el tránsito de la "barbarie" a la "civilización", es decir, desde su "debilidad" infantil inherente hacia la madurez del mundo adulto. En correspondencia con la evolución de la humanidad, el niño quedaba

30 La intención de Fernando Pons de influir en el diseño de un método pedagógico orientado a expandir la escolarización se descubre en su siguiente argumentación: "El hombre, en todas las etapas de su progresivo desarrollo, no puede, como producto que es de la naturaleza, sustraerse a los dictámenes de esta, en la cual está previsto y aún prescrito que los seres deben desarrollarse por partes y según un orden y plan preconcebidos. Cuando el agricultor sepulta el grano de trigo en el seno de la madre tierra, sabe bien que la espiga por él acariciada no aparecerá sino después de haberse desarrollado las otras partes constitutivas de la planta. Así también el espíritu humano, para cosechar el fruto de sus constantes labores debe, en estas, ir por partes, seguir un orden, trazarse un camino... Según esto debe admitirse que tanto para investigar la verdad como para exponerla o enseñarla, hay que ir por partes según un orden y trazarse un camino...”. Fernando Pons, Metodología General...,169. 
naturalizado como un estadio inicial y el maestro como la culminación y síntesis más encumbrada de un proceso de hominización. De esta forma, la perspectiva laicista de la educación se ponía al servicio de la configuración del nuevo orden jerárquico liberal, que dependía de la escolarización masiva de los sujetos, proceso en el cual los normalistas jugaban el papel protagónico.

El pensamiento de Pons influyó de manera decisiva en los jóvenes normalistas, tanto por su condición de director y maestro de la Normal de Varones como del impulso que dio a la creación de las primeras asociaciones gremiales de docentes. Los normalistas estructuraron sus acciones y reflexiones fundamentalmente en torno a la defensa de la enseñanza primaria, el lugar natural que el historicismo positivista les había asignado, para colaborar en la gran tarea civilizatoria que enrumbaba a la humanidad.

¿Cómo conciliaron los maestros el universalismo positivista con un sentido nacional de la enseñanza primaria? En el marco del Primer Congreso Pedagógico Nacional celebrado en 1916, Carlos Alberto Flores, representante de los preceptores del Guayas, hizo una calurosa defensa de la educación primaria usando la metáfora de "la semilla que contiene en sí y por modo maravilloso todas aquellas partes que forman el árbol", en clara alusión al doble papel de aquella en la configuración de la nación y, al mismo tiempo, en el desarrollo de la autonomía individual. En sus palabras, la educación primaria promovía "la prosperidad y grandeza nacionales", formaba "el espíritu y el carácter nacionales", y sacaba al hombre de la ignorancia "haciéndolo señor de sí mismo"; lo que podría entenderse como un llamado a soltar las amarras de la tradición y recrear la base cultural de la nación a partir de la educación elemental como un escenario de refundación del país ${ }^{31}$.

La reivindicación de la primaria llegó a convertirse en bandera de la lucha gremial de los docentes, y en un territorio propio que adquiría mayores contornos a medida que la profesión pedagógica se consolidaba y especializaba. Aún más, en los congresos pedagógicos y las publicaciones de los

31 Periódico El Día, Quito, 15 de agosto de 1916. 
maestros aquella reivindicación significó, al mismo tiempo, la desestimación de otros niveles de instrucción. Se señalaba explícitamente que sin la primaria.
"...nadie puede alcanzar la condición de ciudadano, en cambio la secundaria y la superior, aunque útiles, no "tienen la urgencia que distingue a aquella (...) para la felicidad común importa más en una república que todos los ciudadanos tengan los conocimien- tos de la instrucción primaria antes que en ella resplandezcan Píndaros, Virgilios, Dantes, Corneilles, Herreras, Descartes, Fit- chs, Lavoiessiers..." ${ }^{\prime 2}$.

Estas expresiones no eran simple retórica. La pertinencia misma de la secundaria, un ciclo que no tenía relación con la primaria sino con la educación universitaria ${ }^{33}$, fue criticada por intelectuales y funcionarios que en cierto momento abogaron por su desaparición, en tanto la consideraban innecesaria por representar un modelo del pasado, contrario a los intereses de la educación popular. Defendían una primaria con mayor número de niveles y articulaciones, basada en un currículo gradual y concéntrico dirigido a fortalecer la "educación común" 34 . Era una visión eficientista de la educación popular, cuya metodología de enseñanza reflejaba también la influencia, antes mencionada, del utilitarismo positivista, como se constata en la siguiente declaración formulada durante el Primer Congreso Pedagógico:

"Entre las materias que son del dominio de la instrucción primaria, debe dárseles mayor extensión y profundidad a aquellas que tienen que ver con las artes y oficios a que comúnmente se dedican los habitantes de cada región, ya que la mayor parte de

32 Periódico El Día, Quito, 15 de agosto de 1916.

33 La enseñanza secundaria y universitaria estaban a cargo del Consejo Superior cercano al Ministro; y la primaria, de los Consejos Escolares locales. La escuela primaria se clasificaba en escuelas elementales, medias y superiores.

34 Entre los detractores de la enseñanza secundaria se contaban ministros que habían cerrado expresamente algunos colegios como Luis. A. Martínez y Julio Román. Alfredo Monge expuso los argumentos más sólidos al respecto en Informe del Ministro de Instrucción Pública...1907, 144-145. 
los que asisten a las escuelas salen de ellas para ir derechamente al taller o al campo donde les serán poco menos que inútiles una gran suma de conocimientos adquiridos a costa de tiempo y de trabajo, y que serían excelentes para naciones que llevan distinto género de vida. Este punto acaso no ha sido considerado con madurez hasta ahora..." 35 .

Sin pretender generalizar esta concepción al conjunto del magisterio laico, la cita sugiere que la educación popular fue concebida también como un mecanismo para crear el modelo social y las relaciones de subordinación necesarias para poner en marcha la modernización del país y su "regeneración", sobre todo en lo concerniente a las clases populares.

El debilitamiento de la dimensión anticlerical del laicismo en la etapa posalfarista favoreció la creación de lazos entre maestros laicos y figuras destacadas de la intelctualidad conservadora. Los cursos de capacitación masiva de preceptores, que eran impartidos por las sociedades pedagógicas, contaban entre los conferencistas con miembros de las academias de historia y de la lengua que gozaban de un gran prestigio social. Cuando en 1917 falleció el gran fustigador de la educación Laica, el arzobispo González Suárez, la revista El Magisterio Ecuatoriano, publicada por los jóvenes pedagogos laicos, destinó un número entero a exaltar la figura de quien fue considerado el maestro de maestros ${ }^{36}$.

Pese al esfuerzo secularizador librado hasta esos momentos, las escuelas laicas eran todavía islotes en medio de una marea católica que no cesaba de agitarse. Una noticia de julio de 1916 publicada en el periódico liberal El Día ilustraba esta realidad a propósito del ambiente que los estudiantes vivían al término del año escolar por la rendición de los temidos exámenes finales. Bajo el título "En espera de un milagro", se relataba que "en la capilla de Cantuña donde se venera al taumaturgo San Antonio que hace encontrar lo perdido, se ve diariamente un número crecidísimo de niños de ambos sexos y de profesoras, colocando reverentes cirios a dicho Santo,

35 Periódico El Día, Quito, 15 de agosto de 1916.

36 El Magisterio Ecuatoriano, Revista Mensual de Pedagogía, Quito, diciembre de 1917. 
con las súplicas de que les haga salir bien del examen. Inocente y conmovedor pedido" 37 .

Esta nota irónica de los liberales reflejaba, a su pesar, la poca influencia que hasta la segunda década del siglo XX había alcanzado la educación laica y su sistema de valores sobre el conjunto de las prácticas culturales de una sociedad fuertemente permeada por la religiosidad católica.

\section{El NUEVo dios del LAICISMo COMO disPositivo JERÁRQUico y MORAL}

Las representaciones de una niñez escolarizada subordinada al maestro y al mundo adulto fueron ampliamente difundidas a través de los textos escolares para la enseñanza primaria. En ellos se reveló la voluntad del laicismo por exhibir los fundamentos morales de un nuevo tipo de ordenamiento social y político, que debía partir de la reforma de la infancia.

El texto denominado El Lector Ecuatoriano ${ }^{38}$, constituye un ejemplo vívido de la claudicación del laicismo ante la necesidad de apelar a una matriz religiosa y a estructuras jerárquicas como referentes del orden moral e incluso disciplinario que se estableció por la vía de la instrucción pública. El Lector Ecuatoriano fue elaborado por connotados intelectuales liberales y constituyó un compendio de lecturas dedicado a fomentar la moral, la virtud y el patriotismo, a partir de familiarizar a los niños con ciertos conceptos fundamentales del nuevo ideario laico. Entre los títulos de los capítulos sorprende encontrar las menciones a Dios y a la religión presidiendo el texto, seguidas de los temas alusivos a la Patria, la libertad, el hogar y otros relativos a los roles sociales de hombres, mujeres, jóvenes, soldados, ancianos, pobres obreros, etc. Solo al final se incluyen también lecturas referidas a la escuela laica, la práctica de valores y antivalores, y los símbolos nacionales.

El texto construye una representación esencialista de la infancia, a partir

37 El Día, Quito, 6 de julio de 1916.

38 José Antonio Campos y Modesto Chávez Franco, El Lector Ecuatoriano. Libro tercero para las escuelas primarias (Guayaquil, Imprenta Municipal, 1915). 
de una mirada del conjunto de las relaciones sociales que involucran al niño, y de una perspectiva fuertemente sesgada por una estructura social clasista. Las relaciones de poder y subordinación a que está sometido el niño se distribuyen en múltiples direcciones, hacia Dios, la familia, la sociedad y la Patria. Específicamente, la imagen de Dios presentada por el texto no se corresponde a la tradición católica. Se trata de un dios despersonalizado, de proyección cósmica, una "entidad ignota que rige el universo", cuya amplitud y universalidad cobija a todas las religiones, "solo que cada religión lo cree y llama a su modo... Alá, Jehová, etc.”. Esta representación consagra una ley moral única que rige el mundo, y que no es otra que "amar a Dios sobre todas las cosas y al prójimo como a nosotros mismos", máxima que une todas las creencias del planeta. Los elementos visuales asociados a Dios son cielos estrellados y símbolos esotéricos, expresados por manos celestiales que juntan el alfa y el omega. Ante estos misterios, el niño que mira asombrado tales símbolos reacciona con curiosidad, no con reverencia. Se puede concluir que este imaginario religioso seculariza la religión tradicional y propone un nuevo sistema de valores.

Los mensajes que arroja el texto sobre la estrecha relación entre escolarización e infantilización demuestran que la escuela es considerada por los liberales un espacio de regeneración social indispensable para alcanzar el ideal anhelado de sociedad. A tal punto se extrema esta condición que el niño que no transite por la escuela no es considerado un niño. La lectura referida al Vendedor de Periódicos, lo expresa claramente:

"Esos chicos nos son chicos: son hombres. La edad es corta, la estatura es pequeña; pero son cabezas de familia muchas veces y en todo caso, un alivio inmenso para sus deudos (...) Hay que dejar vivir a estos niños-hombres, de moral deslucida por la miseria del medio ambiente, pero que son grandes benefactores en las bajas capas de la sociedad"39.

El texto también sugiere que en el ideario laicista la estructura de clases es una condición social naturalizada, en la que la pobreza no es un desafío

39 José Antonio Campos y Modesto Chávez Franco, El Lector Ecuatoriano..., 80. 
a superar, sino una condición inamovible que solo debe ser dignificada. Las figuras del trabajador y del obrero aparecen enaltecidas en la obra, precisamente, por los valores de "dignidad de la pobreza" y de la "nobleza" derivada no de la sangre, sino del servicio prestado a la causa de la Patria y del ejercicio honrado del "trabajo", al que se apreciaba como un valor intrínseco y no como diferencia derivada de la situación de clase. Frente al enaltecimiento y naturalización de valores modernos ligados al progreso capitalista, se levantan como contraparte los anti-valores que el texto censuraba: la vagancia, la mentira, el robo, el fraude, todos pecados sociales que el niño debía contribuir a erradicar mediante el cumplimiento del deber, de la caridad, la valentía, la prudencia y la discreción. El discurso de dignificación del trabajo y de la pobreza muestra que la concepción laica de la educación popular, tan apreciada por los liberales, tuvo claras connotaciones regeneradoras.

El Dios cósmico laico también fue representado como vértice del orden moral en el libro Instrucción Moral y Cívica que mayor difusión tuvo en el medio escolar ecuatoriano durante esos años. Su autor, Francisco Paula Soria, dedicó el tercer acápite de la introducción a describir la existencia de un Dios concebido como Causa Suprema y razón de todas las cosas del universo, una condición, que según afirma Soria, estaba refrendada por la ciencia. El plan de este Ser Supremo era considerado indeclinable porque se cumplía en concordancia con las "leyes naturales", que rigen no solo el orden físico sino también el humano. En tanto Dios era la expresión de la perfección, el ser humano debía tender al perfeccionamiento constante mediante el cultivo de la ciencia, la moral y el carácter. Deslindándose de la tradición católica basada en el culto público y las prácticas sociales de religiosidad, el autor recomendaba que el camino para "conocer" y "adorar" a tal Dios implicaba una práctica individual basada en

"El amor al estudio y a las lecturas instructivas, el acatamiento a las opiniones de los sabios, el interés por los descubrimientos científicos y la protección o apoyo a los fines de la ciencia... En resumen los deberes para con Dios son: 1. El amor al estudio, 2. La protección a la ciencia, 3. El cumplimiento de nuestros debe- 
res morales en todas las esferas de la vida: privada, doméstica, social y política" ${ }^{\prime 4}$.

Este párrafo habla del profundo significado que para el liberalismo tenía la emancipación del conocimiento, el camino hacia una ciencia liberada de la teología que, paradójicamente, terminó siendo también sacralizada, como bien lo expresa el texto de instrucción cívica. El Dios laico aparecía ante los escolares como el principio legitimador de un modelo basado en una suerte de cristianismo racionalista, que demandaba de ellos el cumplimiento de nuevos deberes, y la adopción de la fe en el progreso y la supremacía de la ciencia como meta de los destinos individuales. ¿Hasta qué punto esta emancipación intelectual estaba atravesada por un sentido de soberanía para la instrucción pública? Es una cuestión que queda por explorar.

\section{A Manera de CONCLusión}

Las reflexiones expuestas en esta ponencia discuten algunos de los lugares comunes consagrados por la historiografía ecuatoriana en torno a la cuestión del laicismo, uno de los temas más sensibles de la historia contemporánea del Ecuador por cuanto se lo considera una expresión de identidad y modernización conquistada por las clases medias emergentes que rompieron con el esquema aristocrático prevaleciente en el siglo XIX. Con el fin de suscitar un debate, se ha intentado, en primer lugar, historizar el concepto de lacisimo a la luz de los distintos signficados que aquel adoptó en diversos contextos de enunciación, como fueron el debate en torno a los fundamentos de la soberanía y el contraste entre universalismo y sentido nacional. Estas cuestiones interrogan la idea arraigada de que el laicismo siempre tuvo una perspectiva nacional. De otro lado, se constata que el laicismo creó de todas maneras otro tipo de sacralidad alternativa a la católica, que rindió culto a la razón y sirvió para sostener el nuevo sistema moral y jerárquico del liberalismo. Se demuestra, finalmente, que una de las más interesantes apropiaciones sociales del laicismo se concretó en el discurso pedagógico inspirado en el positivismo, por el cual la educación

40 Francisco de Paula Soria, Curso de Instrucción Moral y Cívica. Texto declarado oblgatorio para las escuelas y los colegios de la República del Ecuador (Quito, Imprenta nacional, 1909), 20-22. 
laica encontró un lugar natural en el desarrollo de la historia occidental, cuestión que elevaba al maestro laico a la condición de conductor de la infancia hacia la civilización y el progreso, un camino que, por cierto, no requería una escuela popular igualitaria, sino de una escuela regeneradora que facilitara el tránsito de la "barbarie" a la "civilización". A fin de cuentas la igualdad liberal se ventilaba ante la ley y no en las estructuras sociales.

Una metáfora de la manera cómo la educación laica estuvo condicionada por el legado estructural de la educación católica precedente es una fotografía que apareció en el primer número de la revista Vida Intelectual, publicada en 1911 por los alumnos del Colegio Mejía de Quito ${ }^{41}$; la institución secundaria emblemática de la educación laica ecuatoriana. En ella se puede apreciar a los estudiantes del plantel agrupados en el patio y los pasillos de una edificación de apariencia conventual y colonial que poco tiene que ver con el espíritu secularizador del laicismo. De hecho, en esos momentos el Colegio Mejía estaba ocupando la edificación -captada por la fotografía- de la legendaria escuela de los Hermanos Cristianos establecida en el Ecuador en 1863, que a su vez había sido instalada en el lugar de la primera escuela lancasteriana que tuvo la capital, a la cual el presidente Rocafuerte, en 1834, destinó este edificio, entonces en ruinas, perteneciente al antiguo beaterio colonial de mediados del siglo XVIII, que funcionaba como asilo de mujeres marginales y estaba regentado por religiosos. La fotografía de los alumnos del Colegio Mejía aporta -sin proponérselo- una estratigrafía de la historia de la educación ecuatoriana, creada a base de reformas educativas sucesivas asociadas a grandes transformaciones nacionales, pero que no logran trascender la matriz histórica original basada en la herencia católica. Las distintas ocupaciones del mismo espacio se superponen unas a otras expresando posiblemente la conquista y el triunfo sobre cada proyecto que logró ser derrotado, pero al mismo tiempo la imagen revela la persistencia de estructuras culturales en las que quedaron atrapados los anhelos modernizadores. Solo en 1930, el Colegio Mejía contará con su propio local, este sí de características neoclásicas, que son las que precisamente corresponden a los códigos arquitectónicos formales que la ciudad de Quito adoptó en su primer tránsito a la expansión y modernidad urbanísticas.

41 Vida Intelectual. Organo del Comité 19 de marzo, 1 (Quito, Talleres de El Comercio, 1911). 


\section{Bibliografía}

\section{Fuentes primarias}

Actas de la Asamblea Nacional de 1906, Fondo Constituciones, Archivo del Palacio Legislativo, Ecuador.

Campos, José Antonio y Modesto Chávez Franco. El Lector Ecuatoriano. Libro tercero para las escuelas primarias, Guayaquil: Imprenta $\mathrm{Mu}-$ nicipal, 1915.

Boletín Eclesiástico. Revista de los intereses católicos en el Ecuador, 16, (septiembre 1 de 1906).

El Magisterio Ecuatoriano. Revista Mensual de Pedagogía, 10 (1917).

Periódico El Día, Quito 6 de julio de 1916

Informe del Ministro de Instrucción Pública a la Nación. Quito: Imprenta Nacional, 1907.

Ley Orgánica de Instrucción Pública. Segunda Edición, Quito: Imprenta Nacional, 1907.

Paula Soria, Francisco de. Curso de Instrucción Moral y Cívica. Texto declarado obligatorio para las escuelas y los colegios de la República del Ecuador, Quito: Imprenta Nacional, 1909.

Peralta, José. La cuestión religiosa y el poder público en el Ecuador, Quito: Tipografía de la Escuela de Artes y Oficios, 1901.

Pons, Fernando. Metodología General, en Pensamiento Pedagógico Ecuatoriano, Segunda Parte, Quito: Ministerio de Cultura/Corporación Editora Nacional, 2011.

Vega, Nicolás. "Breves observaciones a la Ley Orgánica de Instrucción Pública”, Quito: Imprenta Nacional, 1906.

Vida Intelectual. Organo del Comité 19 de marzo, 1, Quito, 1911.

\section{Fuentes secundarias}

Ayala M., Enrique. Historia de la revolución liberal, Quito: Corporación Editora Nacional, Taller de Estudios Históricos, 1994.

Ayala M., Enrique. Lucha política y origen de los partidos en Ecuador, Quito: Corporación Editora Nacional-Taller de Estudios Históricos, 1988.

104 Blancarte, Roberto. "Laicité au Mexique et en Amerique Latine. Comparaisons", Archives des Sciencies Sociales des religions, 146 (avril-juin 2009). 
Blancarte, Roberto. "Laicidad y laicismo en América Latina", Estudios Sociológicos, Vol. 26, No. 76 (Jan-Apr., 2008): 139-164.

Gómez, Jorge. Las misiones pedagógicas alemanas y la educación en el Ecuador, Quito: Ediciones Abya Yala, 1993.

Ossenbach, Gabriela. "La secularización del sistema educativo y de la práctica pedagógica: laicismo y nacionalismo". Procesos, Revista Ecuatoriana de Historia, 8 (I sem/1995-II sem/1996): 35-36.

Ossenbach, Gabriela. Formación de los sistemas educativos nacionales en Hispanoamérica, La política educativa como factor de consolidación del Estado Nacional (1870-1900). El caso del Ecuador (Tesis Doctoral en Historia de la Educación, Universidad de Oviedo, UNED, 1988).

Ossenbach, Gabriela. "La educación laica en las reformas liberales del Ecuador entre 1827 y 1912”, École et église en Espagne et en Amérique Latine. Aspects idéologiques et institutionnels, Actes du Colloque de Tours, 4-6 décembre 1987, Publications de l'Université de Tours: 1988, 405434.

Sinardet, Emannuelle. "La pedagogía al servicio de un proyecto político: el herbartismo y el liberalismo en el Ecuador 1895-1925", Procesos: Revista Ecuatoriana de Historia, 13, (II semestre 1998/ I semestre 1999): 25-41.

Terán Najas, Rosemarie. "La escolarización de la vida. El esfuerzo de construcción de la modernidad educativa en el Ecuador (1821-1921)", (Tesis Doctoral en Historia de la Educación, UNED, 2014).

Tobar Donoso, Julio. "La Instrucción Pública de 1830 a 1930. Apuntes para su historia", en El Ecuador en cien años de Independencia, editado por J. Gonzalo Orellana, Quito: Escuela Tipográfica Salesiana, 1930, 277-318.

Para citar este artículo: Terán Najas, Rosemarie. "Laicismo y educación pública en el discurso liberal ecuatoriano (1897-1920): una reinterpretación”, Historia Caribe Vol. XII No. 30 (Enero-Junio 2017): 81-105. DOI: http://dx.doi.org/10.15648/hc.30.2016.4 